\title{
A rare but life-threatening complication of self- bougienage: iatrogenic esophageal foreign body
}
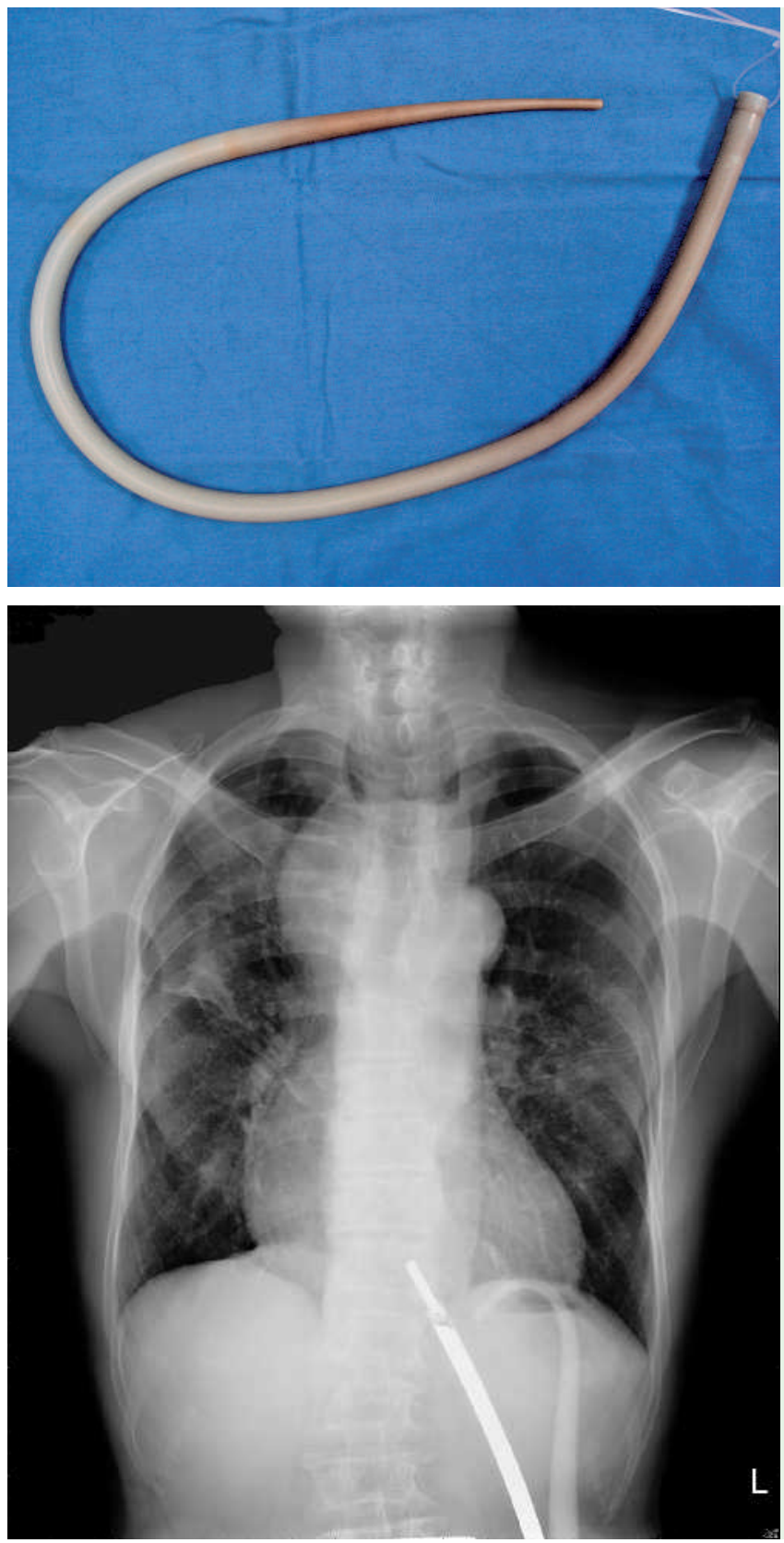

Fig. 1 A 42-Fr mercury-free Maloney esophageal bougie.

Fig. 2 Chest radiography revealed a linear radiopaque foreign body in the lower esophagus and stomach. Dilatation of the esophagus shows air fluid level, which is due to achalasia.

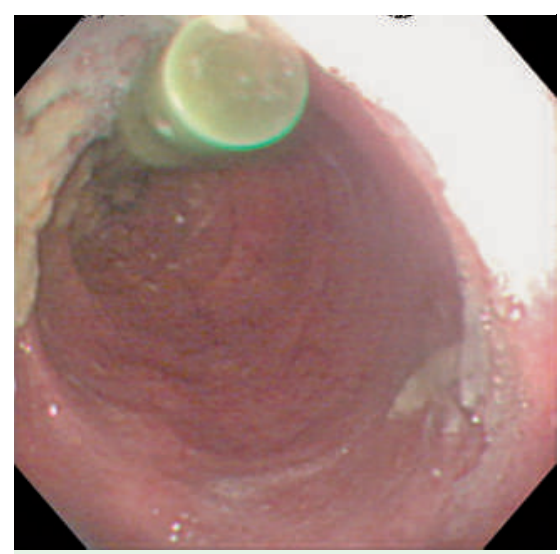

Fig. 3 Endoscopy revealed a Maloney bougie impacted in the distal esophagus.

Bougie dilatation is a routine procedure for benign esophageal stricture for patients in whom surgery is not feasible [1]. Repeated bougienage by the patients themselves, "self-dilation," has been proven safe and effective [2]. The major complication of bougienage is esophageal perforation, although the incidence is only $0.04 \%-0.2 \%$ [3].

Case. A 74-year-old man, diagnosed as achalasia 7 years ago, underwent routine Maloney esophageal bougienation (tungsten filled and mercury free; Rusch, Limerick, Pennsylvania, USA) ( Fig. 1) at our outpatient department at regular intervals. Unfortunately, the patient misswallowed the dilator because of carelessness on 4 December 2006. Chest radiography was done immediately, and revealed a foreign body in the lower esophagus and stomach ( $\bullet$ Fig. 2). An attempt to remove the device with an endoscopic extractor was made ( $\bullet$ Fig. 3 ), and rigid esophagoscopy under general anesthesia was also performed the next morning but in vain. After consultation with a gastrointestinal surgeon, open gastronomic surgery was done, and the dilator was finally removed. The patient achieved uneventful recovery and was discharged 6 days later.

Discussion. Bougie dilatation is the most widely used modality for inoperable pa- 
tients with the motility disorders of the esophagus [1]. Although various complications have been reported $[3,4]$, perforation of the esophagus is the primary concern, and no cases of bougie mis-swallowing have been reported. Most foreign bodies pass harmlessly through the gastrointestinal tract. But if the foreign body is retained, complications will occur and can be lethal. In this case, we could not remove the foreign body by an endoscopic extractor or rigid esophagoscopy, so the external approach seemed to be the best alternative. To prevent this complication, the usual securing wire at the base of the dilator should be as long as the necklace. With this precaution taken, patients can perform self-bougienage safely at home.

Iatrogenic esophageal foreign body following self-bougienage can be life threatening, and prevention is the best policy.

Endoscopy_UCTN_Code_CPL_1AH_2AF

\section{S.-D. Luo, R.-F. Hsu}

Chang Gung Memorial Hospital, Kaohsiung Medical Center, Chang Gung

University College of Medicine, Kaohsiung,

Taiwan

\section{References}

1 Kee ML, Joon HC, Jeong YC et al. The effect of bougienation in benign esophageal stricture: P9. Dig Endosc 2006; 18: A216

2 Grobe JL, Kozarek RA, Sanowski RA. Self-bougienage in the treatment of benign esophageal stricture. J Clin Gastroenterol 1984; 6 : 109-112

3 Harrison ME, Sanowski RA. Mercury bougie dilation of benign esophageal strictures. Hepatogastroenterology 1992; 39: $497-$ 501

4 Thapar VK, Rajashekharam S, Bapat RD et al. Brain abscess following esophageal dilatation. Dis Esophagus 2003; 16: 145-147
Bibliography

DOI 10.1055/s-2007-966948

Endoscopy 2008; 40: E17-E18

(c) Georg Thieme Verlag KG Stuttgart · New York . ISSN 0013-726X

Corresponding author

\section{R.-F. Hsu, MD}

Chang Gung Memorial Hospital, Kaohsiung Medical Center, Chang Gung University College of Medicine, Kaohsiung, Taiwan

123 Ta-Pei Road

Niao-Sung Hsiang

Kaohsiung Hsien

Taiwan

Fax: +886-7-7313855

rsd0323@adm.cgmh.org.tw 